\title{
A Catalytic Hollow Fibre Membrane Reactor for Combined Steam Methane Reforming and Water Gas Shift Reaction
}

\author{
Ana Gouveia Gil, Zhentao Wu, David Chadwick*, K. Li* \\ Department of Chemical Engineering, Imperial College, London SW7 2AZ, United Kingdom
}

(*) Corresponding author. Tel.: +44 207 5945676; Fax: +44 207 5945629. Email: kang.li@imperial.ac.uk

\begin{abstract}
A catalytic hollow fibre membrane reactor (CHFMR) was developed in this study for combined steam methane reforming (SMR) and water gas shift (WGS) reaction. This is achieved by incorporating a Ni/SBA-15 catalyst into a plurality of micro-channels with open entrance from inner surface of $\mathrm{Al}_{2} \mathrm{O}_{3}$ hollow fibres, followed by coating of a $3.3 \mu \mathrm{m} \mathrm{Pd}$ membrane on the outer surface of the hollow fibre using an electroless plating method. In addition to systematic characterizations of each reactor component, i.e. Ni/SBA-15 catalyst, micro-structured ceramic hollow fibre and Pd separating layer, the effect of how the reactor was assembled or fabricated on the catalytic performance was evaluated. Electroless plating of the Pd membrane impaired the catalytic performance of the deposited Ni/SBA-15 catalyst. Also, the over-removal of hydrogen from the reaction zone was considered as the main reason for the deactivation of the Ni-based catalyst. Instead of mitigating such deactivation using "compensating" hydrogen, starting the reaction at higher temperatures was found more efficient in improving the reactor performance, due to a better match between hydrogen production (from the reaction) and hydrogen removal (from the Pd membrane). An effective methane conversion of approximately $53 \%$, a $\mathrm{CO}_{2}$ selectivity of $94 \%$ and a $\mathrm{H}_{2}$ recovery of $43 \%$ can be achieved at $560{ }^{\circ} \mathrm{C}$. In order for a more significant "shift" phenomenon, alternative methodology of fabricating the reactor and more coke resistant catalysts are recommended.
\end{abstract}

Keywords: Catalytic hollow fibre membrane reactor, Steam methane reforming, Water-gas shift, $\mathrm{H}_{2}$ production, Ni/SBA-15 catalyst, Pd membrane 


\section{Introduction}

A catalytic membrane reactor, a unit coupling membrane separation and catalytic reactions, has been studied for a wide spectrum of energy related applications (Armor, 1998; Cornaglia et al., 2013; Mironova et al., 2014; Yang et al., 2014). In addition to potential benefits such as simplified systems and improved synergy, harvesting purified target products via membrane separation is always expected to assist more efficient catalytic reactions. From this point of view, the application of membrane reactor to existing energy and environment related processes is likely to generate innovative solutions to numerous technical challenges (Chaubey et al., 2013).

Pre-combustion decarbonization is one of the three main routes for power generation from fossil fuels with low or no $\mathrm{CO}_{2}$ emission. In this process, fuels such as methane, coal and petroleum are converted into $\mathrm{H}_{2}$ and $\mathrm{CO}_{2}$. The hydrogen as a clean energy carrier can be used for the production of electricity using fuel cells, while the concentrated $\mathrm{CO}_{2}$ is ready for sequestration or chemical fixation in, for example, cyclic carbonates [1]. As thus, the key to the success of the pre-combustion decarbonization approach is the efficient conversion of the hydrocarbon fuels to $\mathrm{H}_{2}$ and $\mathrm{CO}_{2}$, and their separation. Furthermore, achieving this in a single step under relatively mild conditions would lead to a substantial reduction in energy costs (Aasberg-Petersen et al., 1998).

Despite the intensive energy consumption and complicated process, steam methane reforming (SMR) still dominates current industrial processes for $\mathrm{H}_{2}$ production. This is a typical endothermic and thermodynamically controlled reforming reaction that is favoured at high temperatures and low pressures. The CO formed by SMR is further reacted with steam to generate additional $\mathrm{H}_{2}$ via water-gas shift reaction (WGS) (Holladay et al., 2009; Liu et al., 2009).

The use of a membrane reactor allows the in-situ removal of $\mathrm{H}_{2}$, promoting the shift of the SMR reaction towards products, as stated by LeChâtelier's principle (Mengers et al., 2014). Moreover, improving mass and heat transfers of a micro-reactor by enlarging effective surface area and reducing transport distance of a catalytic reaction would further intensify the process (Tonkovich et al., 2007; Tonkovich et al., 2004; Zanfir and Gavriilidis, 2003; Zhai et al., 2010). Therefore, higher methane conversion and $\mathrm{H}_{2}$ yield can be expected at much lower temperatures, and $\mathrm{CO}_{2}$ can be captured at the same time. 
Pd-based membranes have been widely employed for the selective separation of $\mathrm{H}_{2}$, and have been proved efficiently in harvesting $\mathrm{H}_{2}$ in-situ from the catalytic reaction zone of membrane reactors (Hwang et al., 2013; Irfan Hatim et al., 2011; Israni et al., 2009; Maneerung et al., 2014). Meanwhile, the unique micro-channels inside ceramic hollow fibres, fabricated via a viscous-fingering induced phase-inversion process, provide an interesting solution towards a more efficient mass and heat transfer for catalytic reactions (Irfan Hatim et al., 2011). This led to conversions exceeding equilibrium limitations, together with a significantly enhanced productivity rate that indicates a more efficient utilization of the catalyst, especially when the catalyst was incorporated inside the micro-structured ceramic hollow fibres. However, the advantages of this type have been only observed for single reactions, such as ethanol reforming (Rahman et al., 2011), WGS (García-García et al., 2012), propane dehydrogenation (Gbenedio et al., 2010). The effect of membrane separation on catalyst stability, and subsequently the whole catalytic reaction has not yet been investigated for more complicated systems, such as the combined SMR and WGS reaction.

As a result, this proof-of-principle study focuses on the use of a catalytic hollow fibre membrane reactor for the combined SMR and WGS reaction, at operating temperatures significantly lower than normally used for SMR reaction $\left(700-900{ }^{\circ} \mathrm{C}\right)$. The reactor of this type consists of an integrated Pd membrane supported on the outer surface of a highly permeable and micro-structured alumina hollow fibre substrate, where Ni-based catalyst is deposited in large portion of the hollow fibre cross section from inner surface. In contrast to previous reactor counterparts, the ceramic hollow fibre substrates used in this study have micro-channels opened from the inner surface. This facilitates catalyst incorporation and further improves mass and heat transfer throughout the reactor. Apart from characterizing each reactor component (catalyst, hollow fibre substrate and hydrogen separating membrane), this study focuses on the effect of reactor fabrication methodology on performance, as well as outlining key operating parameters in improving the reactor performance.

\section{Experimental}

\subsection{Chemicals and Materials}

The ceramic suspension for hollow fibre fabrication consists of $\alpha-\mathrm{Al}_{2} \mathrm{O}_{3}$ powder $(1 \mu \mathrm{m}$, VWR), dimethyl sulfoxide (DMSO, VWR), arlacel P135 (Uniqema), and polyethersulfone 
(PESf, Ameco Performance) as ceramic material, solvent, dispersant and polymer binder, respectively.

Absolute ethanol (VWR), hydrochloric acid (HCl, 12M, VWR), Pluronic P123 (poly(ethylene glycol)-block-poly(propylene glycol)-block-poly(ethylene glycol) copolymer, MW $=5800$, Sigma Aldrich) and tetraethyl orthosilicate (TEOS, Sigma Aldrich) were used for the preparation of SBA-15 by a sol-gel method. Nickel (II) nitrate hexahydrate $\left(\mathrm{Ni}\left(\mathrm{NO}_{3}\right)_{2} \cdot 6 \mathrm{H}_{2} \mathrm{O}\right.$, Sigma Aldrich) was the metal source for the incipient wetness impregnation of nickel.

The sensitisation and activation solution for Pd membrane deposition were prepared by mixing tin (II) chloride dehydrate (puriss. p.a., Sigma-Aldrich) and palladium (II) chloride (99.999\%, Sigma-Aldrich) with hydrochloric acid (37\%, AnalaR NORMAPUR) and deionized water, respectively. Tetraamminepalladium (II) chloride monohydrate $\left(\mathrm{Pd}\left(\mathrm{NH}_{3}\right)_{4} \mathrm{Cl}_{2} \cdot \mathrm{H}_{2} \mathrm{O}, 99.99 \%\right.$ metals basis, Sigma-Aldrich), ammonium hydroxide $(\mathrm{NaOH}$, $28 \%$ in $\mathrm{H}_{2} \mathrm{O}$, Sigma-Aldrich), EDTA (IDRANAL®III, Riedel-deHaen) and hydrazine hydrate (Sigma-Aldrich) were used to prepare the palladium plating solution.

\subsection{Preparation of micro-structured $\mathrm{Al}_{2} \mathrm{O}_{3}$ hollow fibres}

A highly asymmetric $\mathrm{Al}_{2} \mathrm{O}_{3}$ hollow fibre was prepared by a viscous-fingering induced phaseinversion technique followed by high temperature sintering. Firstly, a homogeneous $\mathrm{Al}_{2} \mathrm{O}_{3}$ suspension of approximately 55 wt. $\% \mathrm{Al}_{2} \mathrm{O}_{3}$ powder, 39.1 wt. \% DMSO, 0.39 wt. \% dispersant and 5.5 wt. \% PESf was prepared via ball milling. After degasing, the ceramic suspension was transferred into $200 \mathrm{~mL}$ stainless steel syringes. The ceramic suspension and bore fluid were co-extruded through a tube-in-orifice spinneret (OD $3.5 \mathrm{~mm}$, ID $1.2 \mathrm{~mm}$ ), both at the same flow rate of $15 \mathrm{mLmin}^{-1}$, into a coagulation bath with no air gap $(0 \mathrm{~cm})$. The hollow fibre precursors were kept in the coagulation bath for a few hours to complete the phase inversion. After straightening and drying, the precursor fibres were sintered in a tubular furnace (Elite TSH17/75/450) at $1400{ }^{\circ} \mathrm{C}$ for $4 \mathrm{~h}$. Prior to the catalyst incorporation, the outer surface of the hollow fibre, with the exception of the central $7 \mathrm{~cm}$, were coated with a gastight glaze by a thermal-treatment at $900{ }^{\circ} \mathrm{C}$ for $1 \mathrm{~h}$. 


\subsection{Deposition of Ni/SBA-15 catalyst into hollow fibres}

The incorporation of Ni/SBA-15 catalyst into hollow fibre was carried out by synthetizing the catalyst in-situ via a two-step process, i.e. incorporation of SBA-15 via a sol-gel method and incipient wet impregnation of nickel nitrate.

A SBA-15 sol was prepared by firstly dissolving $10 \mathrm{~g}$ of Pluronic P123 in $50 \mathrm{~g}$ of ethanol and $2 \mathrm{~g}$ of $\mathrm{HCl}(1 \mathrm{M})$ using a magnetic stirrer, followed by the addition of $20.8 \mathrm{~g}$ TEOS with further stirring. The viscosity of the sol was adjusted by heat treating the solution in a fan oven (Salvislab Thermocenter) at $40{ }^{\circ} \mathrm{C}$ for $12 \mathrm{~h}$. The incorporation of the sol into the hollow fibre was performed by immersing the substrate into the SBA-15 sol under vacuum (a vacuum assisted method). The phase transition from sol to gel was performed in a fan oven at $40{ }^{\circ} \mathrm{C}$ overnight, followed by a calcination step at $600{ }^{\circ} \mathrm{C}$ for $5 \mathrm{~h}$, with a heating rate of 1 ${ }^{\circ} \mathrm{C} \cdot \min ^{-1}$.

The impregnation of $\mathrm{Ni}$ was performed by immersing the $\mathrm{SBA}-15 / \mathrm{Al}_{2} \mathrm{O}_{3}$ hollow fibre in an ethanol based nickel nitrate solution ( $25 \mathrm{wt}$. \% Ni) under vacuum. The evaporation of solvent, i.e. ethanol, was conducted in the fan oven at $40{ }^{\circ} \mathrm{C}$ overnight. The oxidation of $\mathrm{Ni}\left(\mathrm{NO}_{3}\right)_{2}$ to nickel oxide $(\mathrm{NiO})$ was performed in the tubular furnace at $550{ }^{\circ} \mathrm{C}$ for $6 \mathrm{~h}$, with a heating rate of $1^{\circ} \mathrm{C} \cdot \mathrm{min}^{-1}$.

\subsection{Palladium membrane deposition by electroless plating}

The deposition Pd membrane was performed in a two-step process: sensitisation/ activation, aiming at seeding the non-conductive $\mathrm{Al}_{2} \mathrm{O}_{3}$ hollow fibre with $\mathrm{Pd}$ nuclei, and electroless plating as described elsewhere (Gouveia Gil et al., 2015). The sensitisation/ activation was carried out by immersing the substrate sequentially in five different chemical baths: acidic $\mathrm{SnCl}_{2}\left(1 \mathrm{gL}^{-1}\right)$ solution for $5 \mathrm{~min}$, in order to sensitise the support; deionized water for $5 \mathrm{~min}$; acidic $\mathrm{PdCl}_{2}$ solution $\left(0.1 \mathrm{~g} \mathrm{~L}^{-1}\right)$ for $5 \mathrm{~min}$, to form the $\mathrm{Pd}^{0}$ seeds; diluted $\mathrm{HCl}(0.01 \mathrm{M})$ for 2 min, to remove excess of $\mathrm{Sn}^{4+}$ and $\mathrm{Sn}^{2+}$ ions; and deionized water for $3 \mathrm{~min}$, also to remove excess of chemicals. This sequential process was repeated for 8 times in order to ensure a uniform distribution of sufficient $\mathrm{Pd}^{0}$ on the outer surface of the substrate. The electroless plating was then performed by immersing the activated substrate in a Pd plating solution, which was prepared by mixing $1 \mathrm{~g}$ of $\mathrm{Pd}\left(\mathrm{NH}_{3}\right)_{4} \mathrm{Cl}_{2} \mathrm{H}_{2} \mathrm{O}, 10.025 \mathrm{~g}$ of di-sodium ETDA, 49.5 $\mathrm{ml}$ of ammonia and $200.5 \mathrm{ml}$ deionised water. Preceding the electroless plating, Pd plating solution was left to stabilize for at least $16 \mathrm{~h}$. The electroless plating was performed at $60{ }^{\circ} \mathrm{C}$ 
for $1 \mathrm{~h}$, with a solution volume/substrate surface area ratio of 3.5:1. A hydrazine solution (5.6 $\mathrm{mL} \cdot \mathrm{L}^{-1}$ ) was used as a reducing agent (Mardilovich et al., 1998). Two cycles of electroless plating were performed in order to achieve a highly selective and defect-free Pd membrane.

\subsection{Characterization}

The morphology of all catalytic hollow fibre membrane reactor (CHFMR) components, i.e. Pd membrane, alumina hollow fibre substrate and catalyst, was characterized by scanning electron microscopy (SEM, JEOL JSM-5610LV and LEO Gemini 1525 FEG-SEM). Prior to SEM analysis, the samples were gold coated in a vacuum chamber (EMITECH Model K550) for $2 \mathrm{~min}$ at $20 \mathrm{~mA}$ and brush painted with silver. The pore structure and porosity of the $\mathrm{Al}_{2} \mathrm{O}_{3}$ hollow fibre, as well as the catalytic hollow fibres with integrated $\mathrm{Pd}$ membrane, were evaluated by mercury intrusion porosimetry (MIP, Autopore IV 9500, Micrometrics), over a pressure range between $1.5 \times 10^{3}$ and $2.3 \times 10^{8} \mathrm{~Pa}$ and with a set stabilization time of $10 \mathrm{~s}$. ImageJ software was used to measure the inner and outer diameter of the HF and the thickness of the Pd membrane, based on the corresponding SEM images.

\subsection{Catalytic Performance}

The catalytic performance of the different reactor configurations was evaluated using an experimental apparatus shown in

Figure 1. The flow rates of the reactants and sweep gas (Ar) were controlled by individual mass flow controllers (Brooks Instrument, model 5800) with collective reader (Brooks Instrument, model 0254). A syringe pump (Chemix N5000) was used to feed liquid water in a heating coil (1/16' stainless steel tube), which was connected to the reactor. The inlet and outlet pressures were monitored using a digital pressure gauge (Sick, 10bar). The temperature of the tubular furnace (Vecstar SP HVT) was controlled by a temperature controller (CAL 9400) and monitored by a thermocouple located at the central position of the uniform heating zone $(7 \mathrm{~cm})$. The outlet stream was analysed by a gas chromatograph (Varian 3900) with a packed column (shincarbon, part nbr 19808) and the flow rate monitored by a bubble flow meter.

The catalytic hollow fibre (CHF) and catalytic hollow fibre membrane reactor (CHFMR) as shown in 
Figure $1 \mathrm{~A}$ and $1 \mathrm{~B}$, respectively was assembled by introducing the functionalized hollow fibre (30 $\mathrm{cm}$ in length) in a stainless steel tube (OD 1 cm) and sealing both ends using epoxy resin. After placing and centring the reactors inside the furnace, the system was purged thoroughly with $\operatorname{Ar}\left(50 \mathrm{~mL}^{-1} \mathrm{~min}^{-1}\right)$. In CHFMR configuration, both shell and lumen sides were purged under similar conditions. Prior to the evaluation of catalytic performance, the catalyst was reduced from $\mathrm{NiO}$ into $\mathrm{Ni}$ at a set temperature of $400{ }^{\circ} \mathrm{C}$ for $2 \mathrm{~h}$ and under $\mathrm{H}_{2} / \mathrm{Ar}$ atmosphere (10\% for FBR and $\mathrm{CHF}$ and $50 \%$ for CHFMR).

The catalytic performance test was then investigated at a set temperature range between 450 ${ }^{\circ} \mathrm{C}$ and $560{ }^{\circ} \mathrm{C}$, under atmospheric pressure and with the steam to methane ratio of 2 . A stabilization time of $1 \mathrm{~h}$ was adopted for each operating temperature. At the shell side, the sweep gas flow rate of $50 \mathrm{~mL}^{-1} \mathrm{~min}^{-1}$ was kept constant throughout the catalytic performance test of CHFMR.

The overall performance was evaluated based on effective $\mathrm{CH}_{4}$ conversion $\left(\mathrm{X}_{\mathrm{CH}_{4}}\right), \mathrm{CO}_{2}$ selectivity $\left(\mathrm{S}_{\mathrm{CO}_{2}}\right)$ and $\mathrm{H}_{2}$ Recovery $\left(R_{\mathrm{H}_{2}}\right)$, which are defined by the equations below:

$$
\begin{aligned}
& X_{\mathrm{CH}_{4}}=\frac{\left(F_{\mathrm{CO}}+F_{\mathrm{CO}_{2}}\right)}{F_{\mathrm{CH}_{4} \text { Inlet }}} \times 100 \% \\
& S_{\mathrm{CO}_{2}}=\frac{F_{\mathrm{CO}_{2}}}{\left(F_{\mathrm{CO}}+F_{\mathrm{CO}_{2}}\right)} \times 100 \% \\
& R_{\mathrm{H}_{2}}=\frac{F_{\mathrm{H}_{2} \text { Shell }}}{\left(F_{\mathrm{H}_{2} \text { Shell }}+F_{\mathrm{H}_{2} \text { Lumen }}\right)}
\end{aligned}
$$

where $\mathrm{F}_{\mathrm{CH}_{4}}, \mathrm{~F}_{\mathrm{CO}}, \mathrm{F}_{\mathrm{CO}_{2}}, F_{\mathrm{H}_{2} \text { Shell }}$, and $F_{\mathrm{H}_{2} \text { Lumen }}$ are the flow rates $\left(\mathrm{mol} \cdot \mathrm{min}^{-1}\right)$ of methane, carbon monoxide, carbon dioxide and hydrogen in shell and lumen, respectively. The possible carbon formation associated with these experiments was estimated at no higher than $8 \%$, according to the carbon mass balance calculated based on methane, $\mathrm{CO}$ and $\mathrm{CO}_{2}$. However, post-reaction characterizations did not manage to confirm this, due to the fact that a small amount of catalyst was dispersed throughout the alumina hollow fibre. 


\section{Results and discussions}

\subsection{Micro-structures of the catalytic hollow fibre membrane reactor (CHFMR)}

\subsubsection{Hollow fibre substrate}

Figure 2 presents the SEM images of the $\mathrm{Al}_{2} \mathrm{O}_{3}$ hollow fibre microstructure, with an outer and inner diameter of 2.8 and $2.2 \mathrm{~mm}$, respectively. The formed hollow fibres presented a highly asymmetric microstructure with a plurality of self-organized micro-channels occupying more than $90 \%$ of the cross-section and ideal for catalyst deposition, and a thin and continuous outer sponge-like layer for the coating of Pd membrane. Each micro-channel can be considered as a micro-reactor with more efficient heat and mass transfer efficiencies, due to the characteristic confined dimensions. In contrast to the previous hollow fibre counterparts, in which there is a skin layer on the inner surface with a packed-pore network, these micro-channels have one end directly and fully open on the inner surface, as can be seen in Figure $2 \mathrm{~B}$ and 2C. As a result, the deposition of catalyst throughout the whole channel is facilitated. Moreover, a considerable number of openings on the inner surface are well larger than $10 \mu \mathrm{m}$, which indicates negligible external diffusion resistance for both reactants and products ( $\mathrm{Li}$ et al., 2000). With regards to the outer surface, which is shown in Figure 2D, the uniform packed-pore network and smooth surface facilitate the coating of a thin Pd membrane for hydrogen separation. The overall porosity of the hollow fibre is approximately $64 \%$.

\subsubsection{Deposition of Ni/SBA-15 catalyst}

Despite the large micro-channel entrances (Figure 2C), the selected catalyst (Ni/SBA-15) was incorporated into the hollow fibre via a two-step method, i.e. sol-gel process followed by impregnation. This methodology was selected since it has been proved effective for catalyst deposition in substrates of this type (Gallegos-Suárez et al., 2014; García-García and Li, 2013). A SBA-15 and Ni loadings of approximately $8 \%$ and $3 \%$ were obtained, based on the weight gain after incorporating SBA-15 and $\mathrm{Ni}$, respectively.

Figure 3 shows the SEM images of the Ni/SBA-15 catalyst dispersed throughout the $\mathrm{Al}_{2} \mathrm{O}_{3}$ hollow fibre. The characteristics of catalyst layer vary slightly along the micro-channels, as shown in Figure 3A1. The narrower top region of the micro-channel presents a thicker 
catalyst layer with cracks as shown in Figure 3A2, while the wider region close to the inner surface shows a more uniform and continuous distribution of the catalyst as shown in Figure 3A3. A discrepancy of this type might be related to the amount of SBA-15 precursor deposited in each region with different dimensions and, possibly different evaporation rate of ethanol when SBA-15 sol was converted into gel. Moreover, the SBA-15 layer did not block, partially or fully, the micro-channels entrances, as indicated by Figure 3B1. A thin SBA-15 layer is also present on the inner surface, covering the parts between micro-channel entrances (Figure 3B2).

A uniform distribution of $\mathrm{NiO}$ particles can be observed throughout the hollow fibre, which includes the whole micro-channel (Figure 3A4), packed-pore network (Figure 3A5) and the inner surface (Figure 3B2-B3).

\subsubsection{Electroless plated Pd membrane for $\mathrm{H}_{2}$ separation}

As expected, a defect-free $\mathrm{Pd} / \mathrm{Al}_{2} \mathrm{O}_{3} \mathrm{HF}$ composite membrane, presenting a uniform $\mathrm{Pd}$ membrane of approximately $3.3 \mu \mathrm{m}$ in thickness, was obtained by the electroless plating method. SEM images of both cross-sectional (Figure 4A) and top surface (Figure 4B) suggest the formation of a dense Pd membrane with high integrity and no pin-holes. The integrity of the membrane was further confirmed separately at both room temperature and $450{ }^{\circ} \mathrm{C}$, at the maximum operating pressure of around 18 Psi and under argon atmosphere.

In order to investigate the impact of catalyst incorporation, as well as $\mathrm{Pd}$ membrane deposition, on the microstructures of the hollow fibre, a detailed assessment of pore size and pore-size distribution was carried out by Mercury Intrusion Porosimetry (MIP) and presented in Figure 5. The pore-size distribution of the $\mathrm{Al}_{2} \mathrm{O}_{3}$ hollow fibre follows a bimodal behaviour. The first peak at $0.22 \mu \mathrm{m}$ corresponds to the pore size of the packed pore-network; and, the second peak, varying between 5 and $25 \mu \mathrm{m}$, indicates the openings of the micro-channels on the inner surface. Neither the incorporation of the catalyst nor the deposition of the Pd membrane affected the dimensions of the micro-channels entrances, since the corresponding peak did not present significant changes. This is in accordance with Figure 3B1. In contrast, the peak representing the pore size of the packed-pore network, including the outer spongelike layer and walls between micro-channels, indicates lowered porosity and slightly smaller pore size after incorporating catalyst and coating Pd membrane. This suggests that $\mathrm{Pd}$ penetrates into the substrate and catalyst is deposited not only inside the micro-channels, but also throughout the packed-pore network (Figure 3A5). Furthermore, the formation of a 
catalyst layer along the micro-channel can also lead to decreased surface pore size of the micro-channel wall, as suggested in Figure 3A2-A4, and result in the slight shift of the peak towards smaller pore size as shown in MIP analysis.

The deposition of the Pd membrane onto the hollow fibre had a slight impact on the pore size of the packed-pore network of the sponge-like structures, as suggested by the shifting and slightly lower intensity of the MIP corresponding peak. This is caused by the intrusion on Pd into the substrate, which leads to the formation of an intermediate layer (Gouveia Gil et al., 2015).

The overall changes in the pore size distribution of the CHFMR can be described as a combination of the variations observed for NiO/SBA-15 CHF and $\mathrm{Pd} / \mathrm{Al}_{2} \mathrm{O}_{3}$ HF composite membrane, as shown in Figure 5.

\subsection{Catalytic performance of CHFMR}

In addition to the quality of the catalyst and the membrane, the overall performance of the resultant membrane reactor can be affected by additional factors, such as how the membrane reactor is assembled and how the catalyst and the membrane perform under the membrane reactor conditions that can be quite different from those for testing the catalyst and membrane separately. During the course of assembling the catalytic hollow fibre membrane reactor, Ni/SBA-15 was first deposited inside the micro-structured alumina hollow fibre substrate, which is same as fabricating CHFs, followed by the electroless plating of $\mathrm{Pd}$ membrane onto the outer surface of the porous alumina hollow fibre substrate. After assembling the CHFMR, a catalytic performance test was followed. Despite of the excellent performance of each CHFMR component when characterized separately, e.g. high catalytic performance of CHF and high permeation flux in $\mathrm{Pd} / \mathrm{Al}_{2} \mathrm{O}_{3}$ HF composite membrane (Gouveia Gil et al., 2015), the first CHFMR tested did not show catalytic activity between 375 and $550{ }^{\circ} \mathrm{C}$. In order to address the possible reasons leading to this phenomenon, as well as outlining candidate solutions to deal with this unexpected observation, several experiments were designed to investigate the following factors: potential catalyst leaching during electroless plating, effect of in-situ hydrogen removal and effect of "kicking-off" reaction temperature. 


\subsubsection{Effect of catalyst leaching on reactor performance}

Due to the highly porous nature of the alumina hollow fibre substrate, chemicals involved in the electroless plating of Pd membrane, such as ammonia and EDTA, can infiltrate into the substrate and consequently interact with the Ni/SBA-15 deposited, partially leaching out or contaminating the catalytic active phase of the CHFMR. As a result, the Pd membrane surface of a CHFMR was deliberately blocked to stop hydrogen permeation, which was then used to compare with a CHF (without Pd membrane) to evaluate the impact of electroless plating on the catalytic activity. In this case, the only difference between these two reactors is possible changes in the catalysts during the electroless plating of the Pd membrane.

As can be seen in Figure 6, the effective $\mathrm{CH}_{4}$ conversion of CHF configuration is close to the thermodynamic equilibrium value and is significantly higher than the CHFMR that was operated as a CHF. This suggests that part of the catalyst was either contaminated or leached out during the electroless plating, as the only difference between the two configurations is the coating of a Pd membrane via electroless plating. For $\mathrm{CHF}$, the methane conversion increases with elevated temperatures, reaching around $42 \%$ at $560{ }^{\circ} \mathrm{C}$. On the other hand, for the CHFMR, the effective methane conversion is considerably lower, $21 \%$ at both $538^{\circ} \mathrm{C}$ and $560{ }^{\circ} \mathrm{C}$. As expected, from the thermodynamic point of view, the $\mathrm{CO}_{2}$ selectivity decreases with the increase of temperatures. However, similarly to methane conversion, the $\mathrm{CO}_{2}$ selectivity of CHFMR (operated as CHF) at temperatures of $538{ }^{\circ} \mathrm{C}$ and $560{ }^{\circ} \mathrm{C}$ is similar, $94.7 \%$ and $95.10 \%$, respectively, and is higher than the CHF. Despite of the significantly higher methane conversion, the $\mathrm{CO}_{2}$ selectivity of $\mathrm{CHF}$ configuration at low temperatures is similar to CHFMR.

By comparing the two reactor configurations above mentioned, it is clear that electroless plating of the Pd membrane would reduce the overall catalytic activity of the catalyst deposited inside the micro-channels, and is one of the reasons affecting the overall performance of the membrane reactor. Moreover, the CHFMR that was operated as a CHF was proved with certain catalytic performance, when there was no in-situ removal of hydrogen via the Pd membrane. In comparison with the first CHFMR that deliver no catalytic performance, it is worth to investigate the role of removing hydrogen via the Pd membrane in affecting the membrane reactor performance. 


\subsubsection{Effect of in-situ $\mathrm{H}_{2}$ removal}

SMR can be considered as a coke-intensive reaction, in which the produced hydrogen can rapidly remove reactive coke precursors from the $\mathrm{Ni}$ active sites and, as a result, reduce carbon formation and lastly avoid deactivation of the catalyst (Bartholomew, 2001; Hou and Hughes, 2001; Pedernera et al., 2007). Furthermore, the presence of hydrogen can reverse the blockage of catalytic sites by chemisorption of hydrocarbons and mitigate the sintering of $\mathrm{Ni}$ particles, which can rapidly grow under atmospheres containing oxygen and water vapour (Bartholomew, 2001). The hydrogen can also prevent an adapted oxidation state of $\mathrm{Ni}$ (Miachon and Dalmon, 2004) and reduce residual NiO particles. Although electroless plating leads to the loss of catalyst activity, as discussed above, the remained catalyst is still active to the reaction (Figure 6). Therefore, the poor performance of CHFMR can also be related to the in-situ remove of $\mathrm{H}_{2}$ under the membrane reactor conditions. As a result, $5 \mathrm{mLmin}^{-1}$ of "compensating" $\mathrm{H}_{2}$ were added in either the shell or the lumen of the CHFMR, for the purpose of mitigating the hydrogen permeation through the Pd membrane or increasing the hydrogen concentration at the reaction side.

Figure 7 shows the effective methane conversion (Figure $7 \mathrm{~A}$ ) and $\mathrm{CO}_{2}$ selectivity (Figure 7 B) of the CHFMR operated at different conditions, as well as the one of CHF for comparison purpose. The addition of $\mathrm{H}_{2}$, i.e. lumen or shell, was beneficial and contributed to improved methane conversions, in contrast to no reaction of the first CHFMR. This addresses the importance of maintaining a certain concentration of $\mathrm{H}_{2}$ in the reaction zone in suppressing the deactivation of $\mathrm{Ni}$. The supply of $\mathrm{H}_{2}$ at the reaction zone (lumen) played a more significant role since higher effective methane conversions were achieved (e.g. $22.2 \%$ at 562 ${ }^{\circ} \mathrm{C}$ for CHFMR - Lumen and $7.4 \%$ at $553{ }^{\circ} \mathrm{C}$ for CHFMR - Shell). This might be due to an improved contact between catalyst and $\mathrm{H}_{2}$, when fed in lumen. The trend observed for $\mathrm{CO}_{2}$ selectivity was as expected. It should be noted here that, although the supplemented $\mathrm{H}_{2}$ helps to reduce the deactivation of catalyst, the overall performance is still below the CHF. Meanwhile, the SMR reaction is limited thermodynamically and, as a result, the addition of extra hydrogen actually suppresses the methane conversion and is not suggested.

Figure 7 also indicates that, in order for maintaining certain catalytic activity of the catalyst deposited, certain amount of hydrogen produced from the reaction is actually preferred to be retained at the reaction side, instead of being fully removed via the Pd membrane to pursue high $\mathrm{H}_{2}$ recovery. Or in another word, from operating membrane reactor point of view, the 
reaction can be started at the conditions when sufficient produced hydrogen can still remain at the reaction side, after the rest hydrogen being removed via the Pd membrane.

\subsubsection{Effect of "kicking-off" operating temperatures}

In order for approaching the reaction conditions above mentioned, three "kicking-off" temperatures were investigated separately, using one CHFMR for each temperature selected. (Figure 8). A higher "kicking-off" temperature is expected to generate more produced hydrogen, thus increasing the chance of maintaining the catalyst activity when the in-situ hydrogen removal proceeds at the same time. As can be seen in Figure 8A, methane conversion of the CHFMR at $462{ }^{\circ} \mathrm{C}$ is considerably higher than the CHFMR operated as a CHF (Figure 6) and those with "compensating" hydrogen (Figure 7). This indicates that catalyst deactivation due to the over removal of hydrogen, especially at low operating temperatures, is the major reason for the poor performance of the first CHFMR. In comparison to $\mathrm{CHF}$, the methane conversion of CHFMR at $462{ }^{\circ} \mathrm{C}$ is lower, which may be attributed to the loss or contamination of $\mathrm{Ni}$ caused during the electroless plating of the $\mathrm{Pd}$ membrane (Figure 6). As the starting operating temperature increases, the methane conversion of CHFMR becomes closer to the CHF, as well as to the equilibrium conversion of the combined SMR and WGS reaction. Finally, at $560{ }^{\circ} \mathrm{C}$ the catalytic performance of the CHFMR exceeds the CHF and is slightly above the equilibrium. Figure 8A also indicates that, despite of possibly a less amount or less active catalyst inside CHFMR (Figure 6), hydrogen separation via the Pd membrane still contributes to improved performance over $\mathrm{CHF}$, although it appears at high operating temperatures and is based on careful selection of reaction conditions.

$\mathrm{CO}_{2}$ selectivity of $\mathrm{CHF}$ configuration decreases with the increasing temperature (Figure $8 \mathrm{~B}$ ), which is in alignment with thermodynamic behaviour of WGS reaction. On the other hand, for CHFMR, $\mathrm{CO}_{2}$ selectivity increases at $575{ }^{\circ} \mathrm{C}$ (from $91 \%$ to $94 \%$ ), which is an indication that hydrogen removal further assists the production of $\mathrm{CO}_{2}$ by shifting the reaction towards products side.

In order to evaluate the quantity of $\mathrm{H}_{2}$ permeated through the membrane, the $\mathrm{H}_{2}$ recovery was evaluated. As shown in Figure $8 \mathrm{C}$, the $\mathrm{H}_{2}$ recovery increased with elevated temperatures, as expected since the $\mathrm{H}_{2}$ permeation occurs via a solution-diffusion mechanism, which strongly depends on operating temperatures. The sweep-gas flow rate adopted $\left(50 \mathrm{~mL} \cdot \mathrm{min}^{-1}\right)$ was lower than the total flow rate of reactants in order to reduce the driving-force across the 
membrane and, as a result, mitigating the over removal of $\mathrm{H}_{2}$ and the deactivation of the catalyst. This might be the reason for the lower recovery achieved at low temperatures, since the concentration of $\mathrm{H}_{2}$ in the reaction zone is low. Moreover, at $560{ }^{\circ} \mathrm{C}$ the $\mathrm{H}_{2}$ recovery reaches the highest value, approximately $43 \%$, without causing a negative impact in catalytic performance as the $\mathrm{H}_{2}$ concentration at the reaction side is still high $(\approx 7 \%)$. This value is very similar to the one in the outlet stream of CHF, i.e. $9 \%$ at $560{ }^{\circ} \mathrm{C}$.

\section{Conclusions}

A catalytic hollow fibre membrane reactor (CHFMR) was successfully developed by incorporating a Ni/SBA-15 catalyst into micro-channels, and coating a $3.3 \mu \mathrm{m}$ Pd membrane on the outer surface of a highly micro-structured $\mathrm{Al}_{2} \mathrm{O}_{3}$ hollow fibre. The initial low catalytic performance of the assembled CHFMR was mainly caused by the over removal of $\mathrm{H}_{2}$ from the reaction zone, especially at low temperatures, leading to an insufficient amount of the hydrogen at the reaction side and consequently catalyst deactivation. The addition of $\mathrm{H}_{2}$ in either reaction (lumen) or permeate (shell) zones improved the effective methane conversion of CHFMR, proving that a certain amount of hydrogen is preferred at the reaction size. However, the overall performance of the CHFMR with $\mathrm{H}_{2}$ addition did not reach the one achieved by CHF. This was attributed to the partial deactivation of Ni caused by leaching and poisoning of catalyst during the electroless plating, as suggested by the lower catalytic performance of CHFMR without $\mathrm{H}_{2}$ removal when compared to CHF.

With the purpose of a better matching between hydrogen production and removal rates, the effect of "kicking-off" temperature on the catalytic performance of CHFMR was evaluated. The performance of the CHFMR reaches similar values, at $538^{\circ} \mathrm{C}$, or overcome the $\mathrm{CHF}$, at $560{ }^{\circ} \mathrm{C}$, by achieving an effective methane conversion of $53 \%$, a $\mathrm{CO}_{2}$ selectivity of $94 \%$ and $\mathrm{a}_{2}$ recovery of $43 \%$. This suggests that hydrogen removal further assists the conversion of methane by shifting the reaction towards products side.

\section{Acknowledgements}

The authors gratefully acknowledge the research funding provided by EPSRC in the United Kingdom (Grant nos.: EP/ I010947/1). 


\section{References}

Aasberg-Petersen, K., Nielsen, C.S., Jørgensen, S.L., 1998. Membrane reforming for hydrogen. Catalysis Today 46, 193-201.

Armor, J.N., 1998. Applications of catalytic inorganic membrane reactors to refinery products. Journal of Membrane Science 147, 217-233.

Bartholomew, C.H., 2001. Mechanisms of catalyst deactivation. Applied Catalysis A: General 212, 1760.

Chaubey, R., Sahu, S., James, O.O., Maity, S., 2013. A review on development of industrial processes and emerging techniques for production of hydrogen from renewable and sustainable sources. Renewable and Sustainable Energy Reviews 23, 443-462.

Cornaglia, C.A., Tosti, S., Sansovini, M., Múnera, J., Lombardo, E.A., 2013. Novel catalyst for the WGS reaction in a Pd-membrane reactor. Applied Catalysis A: General 462-463, 278-286.

Gallegos-Suárez, E., García-García, F.R., González-Jiménez, I.D., Rodríguez-Ramos, I., Guerreo-Ruiz, A., Li, K., 2014. Ceramic hollow fibres catalytic enhanced reactors for glycerol steam reforming. Catalysis Today 233, 21-30.

García-García, F.R., Li, K., 2013. New catalytic reactors prepared from symmetric and asymmetric ceramic hollow fibres. Applied Catalysis A: General 456, 1-10.

García-García, F.R., Torrente-Murciano, L., Chadwick, D., Li, K., 2012. Hollow fibre membrane reactors for high $\mathrm{H} 2$ yields in the WGS reaction. Journal of Membrane Science 405-406, 30-37.

Gbenedio, E., Wu, Z., Hatim, I., Kingsbury, B.F.K., Li, K., 2010. A multifunctional Pd/alumina hollow fibre membrane reactor for propane dehydrogenation. Catalysis Today 156, 93-99.

Gouveia Gil, A., Reis, M.H.M., Chadwick, D., Wu, Z., Li, K., 2015. A highly permeable hollow fibre substrate for $\mathrm{Pd} / \mathrm{Al} 2 \mathrm{O} 3$ composite membranes in hydrogen permeation. International Journal of Hydrogen Energy 40, 3249-3258.

Holladay, J.D., Hu, J., King, D.L., Wang, Y., 2009. An overview of hydrogen production technologies. Catalysis Today 139, 244-260.

Hou, K., Hughes, R., 2001. The kinetics of methane steam reforming over a Ni/a-Al2O catalyst. Chemical Engineering Journal 82, 311-328.

Hwang, K.-R., Lee, S.-W., Ryi, S.-K., Kim, D.-K., Kim, T.-H., Park, J.-S., 2013. Water-gas shift reaction in a plate-type Pd-membrane reactor over a nickel metal catalyst. Fuel Processing Technology 106, 133-140.

Irfan Hatim, M.D., Tan, X., Wu, Z., Li, K., 2011. Pd/Al2O3 composite hollow fibre membranes: Effect of substrate resistances on $\mathrm{H} 2$ permeation properties. Chemical Engineering Science 66, 1150-1158.

Israni, S.H., Nair, B.K.R., Harold, M.P., 2009. Hydrogen generation and purification in a composite Pd hollow fiber membrane reactor: Experiments and modeling. Catalysis Today 139, 299-311.

Li, K., Kong, J., Tan, X., 2000. Design of hollow fibre membrane modules for soluble gas removal. Chemical Engineering Science 55, 5579-5588.

Liu, K., Song, C., Subramani, V., 2009. Hydrogen and Syngas Production and Purification Technologies. Wiley.

Maneerung, T., Hidajat, K., Kawi, S., 2014. Ultra-thin (\&lt;1\&\#xa0; $\mu \mathrm{m}$ ) internally-coated Pd-Ag alloy hollow fiber membrane with superior thermal stability and durability for high temperature $\mathrm{H} 2$ separation. Journal of Membrane Science 452, 127-142.

Mardilovich, P.P., She, Y., Ma, Y.H., Rei, M.-H., 1998. Defect-free palladium membranes on porous stainless-steel support. AIChE Journal 44, 310-322.

Mengers, H., Benes, N.E., Nijmeijer, K., 2014. Multi-component mass transfer behavior in catalytic membrane reactors. Chemical Engineering Science 117, 45-54.

Miachon, S., Dalmon, J.-A., 2004. Catalysis in Membrane Reactors: What About the Catalyst? Topics in Catalysis 29, 59-65. 
Mironova, E.Y., Ermilova, M.M., Orekhova, N.V., Muraviev, D.N., Yaroslavtsev, A.B., 2014. Production of high purity hydrogen by ethanol steam reforming in membrane reactor. Catalysis Today 236, Part A, 64-69.

Pedernera, M.N., Piña, J., Borio, D.O., 2007. Kinetic evaluation of carbon formation in a membrane reactor for methane reforming. Chemical Engineering Journal 134, 138-144.

Rahman, M.A., García-García, F.R., Hatim, M.D.I., Kingsbury, B.F.K., Li, K., 2011. Development of a catalytic hollow fibre membrane micro-reactor for high purity $\mathrm{H} 2$ production. Journal of Membrane Science 368, 116-123.

Tonkovich, A.L.Y., Yang, B., Perry, S.T., Fitzgerald, S.P., Wang, Y., 2007. From seconds to milliseconds to microseconds through tailored microchannel reactor design of a steam methane reformer. Catalysis Today 120, 21-29.

Tonkovich, A.Y., Perry, S., Wang, Y., Qiu, D., LaPlante, T., Rogers, W.A., 2004. Microchannel process technology for compact methane steam reforming. Chemical Engineering Science 59, 4819-4824.

Yang, Z., Zhang, Y., Ding, W., 2014. Investigation on the reforming reactions of coke-oven-gas to H2 and $\mathrm{CO}$ in oxygen-permeable membrane reactor. Journal of Membrane Science 470, 197-204.

Zanfir, M., Gavriilidis, A., 2003. Catalytic combustion assisted methane steam reforming in a catalytic plate reactor. Chemical Engineering Science 58, 3947-3960.

Zhai, X., Ding, S., Cheng, Y., Jin, Y., Cheng, Y., 2010. CFD simulation with detailed chemistry of steam reforming of methane for hydrogen production in an integrated micro-reactor. International Journal of Hydrogen Energy 35, 5383-5392. 

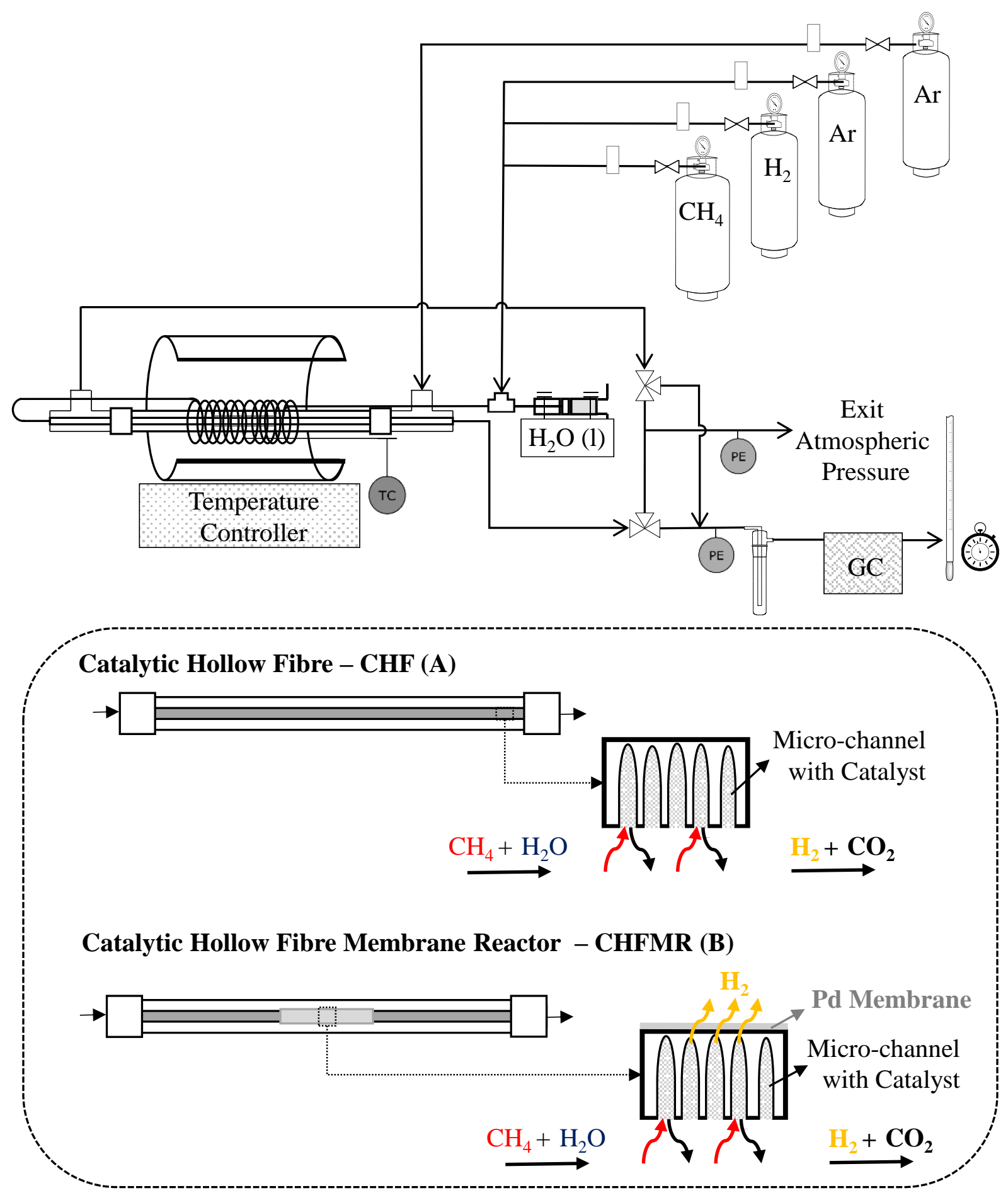

Figure 1 - Schematic representation of experimental apparatus and different reactor configurations. 

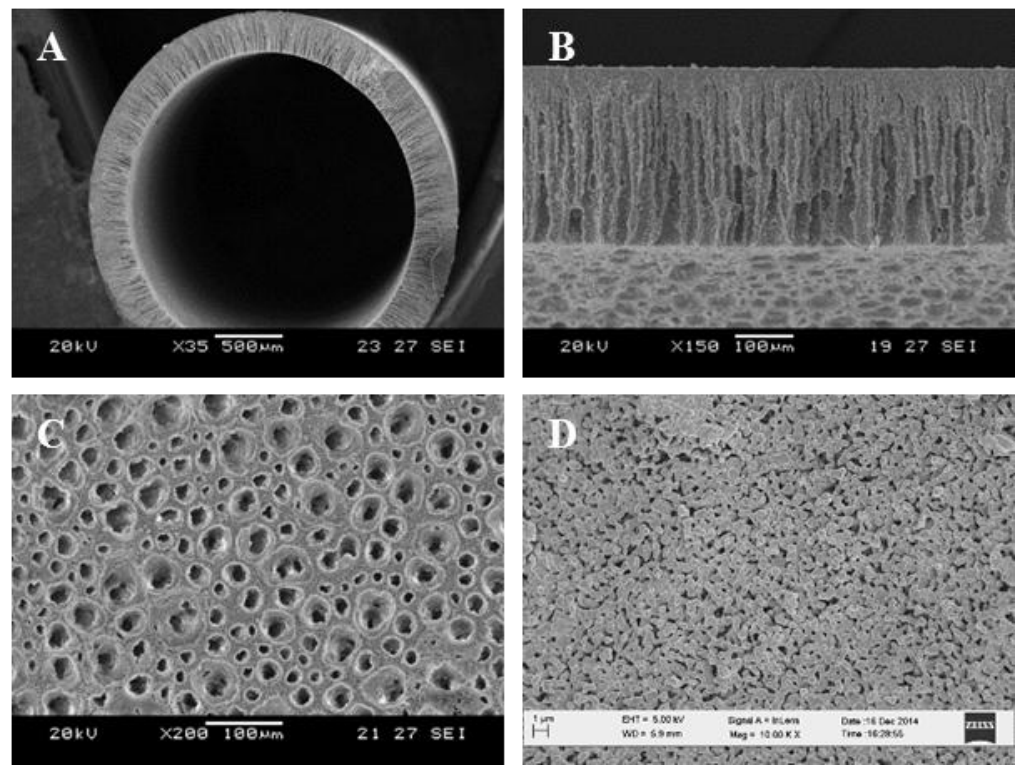

Figure 2 - SEM images of $\mathrm{Al}_{2} \mathrm{O}_{3}$ hollow fibre: (A) whole view; (B) cross section; (C) inner surface; and (D) outer surface. 

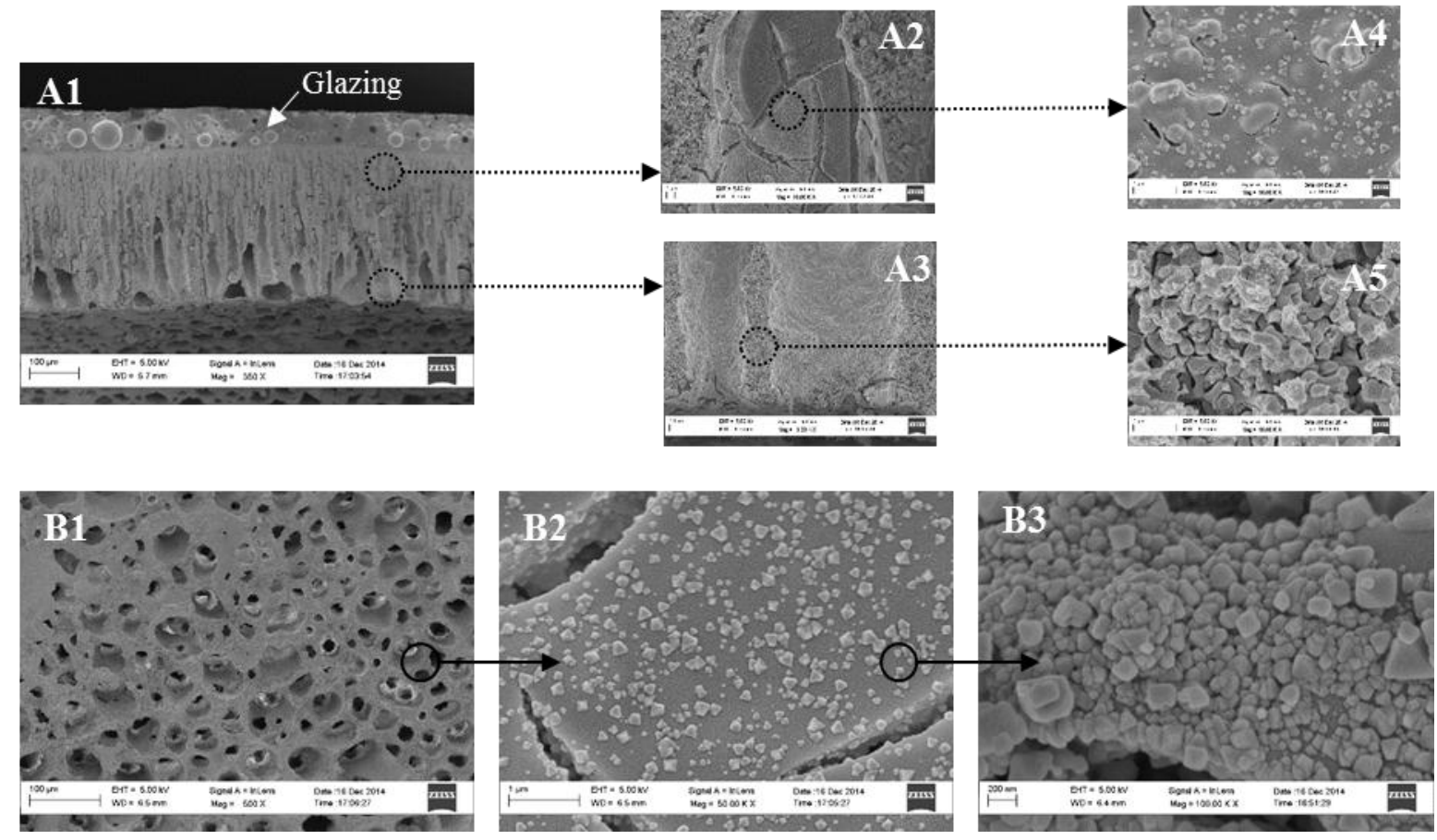

Figure 3 - SEM images of NiO/SBA-15 distribution in CHFMR: global cross section (A1); Ni/SBA-15 catalyst at the top narrow (A2) and lower width (A3) regions of the microchannel; A4 is an higher magnification of A2; channel wall between micro-channels (A5); global inner surface (B1); and B2 and B3 are higher magnifications of B1. 

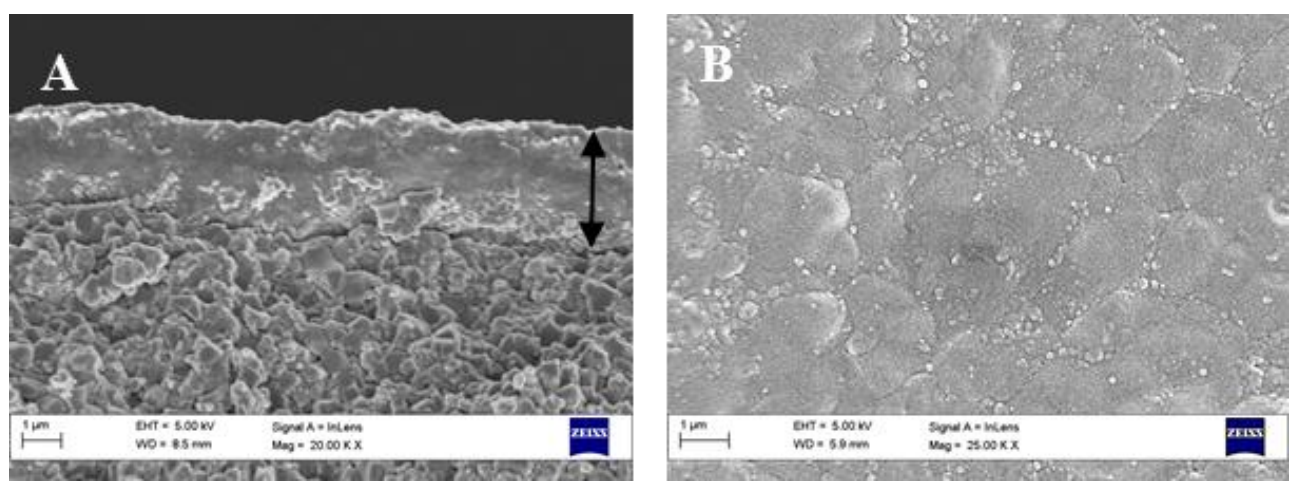

Figure 4 - SEM images of the Pd membrane of CHFMR: (A) cross-section and (B) top surface of Pd membrane. 


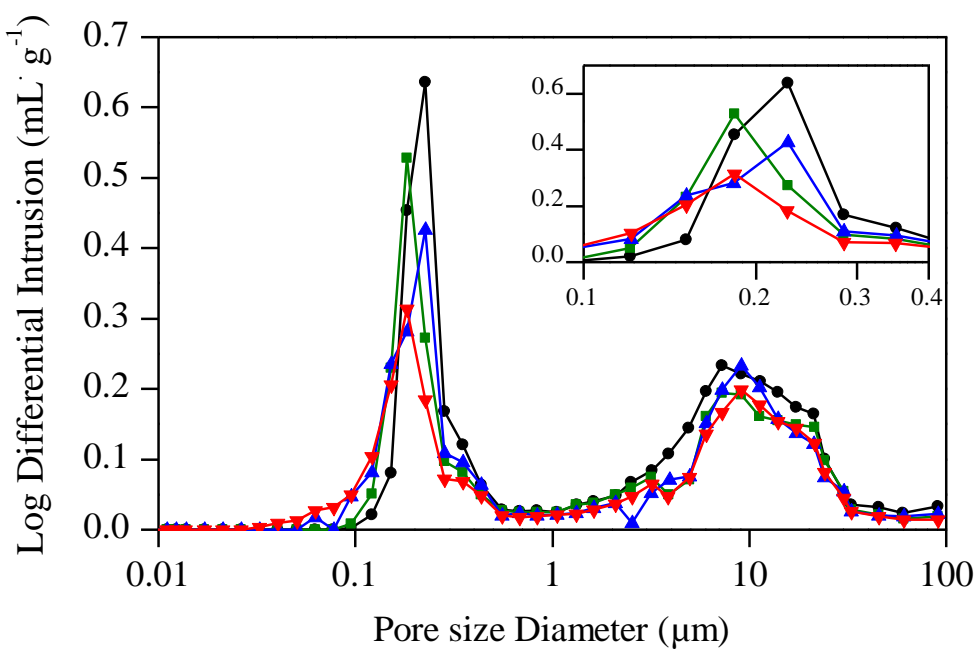

$\longrightarrow \mathrm{Al}_{2} \mathrm{O}_{3} \mathrm{HF} \longrightarrow \mathrm{Pd} / \mathrm{Al}_{2} \mathrm{O}_{3} \mathrm{HF} \longrightarrow \mathrm{NiO} / \mathrm{SBA}-15 \mathrm{CHF} \longrightarrow \mathrm{CHFMR}$

Figure 5 - MIP results of the $\mathrm{Al}_{2} \mathrm{O}_{3} \mathrm{HF}, \mathrm{CHF} \mathrm{Pd} / \mathrm{Al}_{2} \mathrm{O}_{3} \mathrm{HF}$ and CHFMR. 

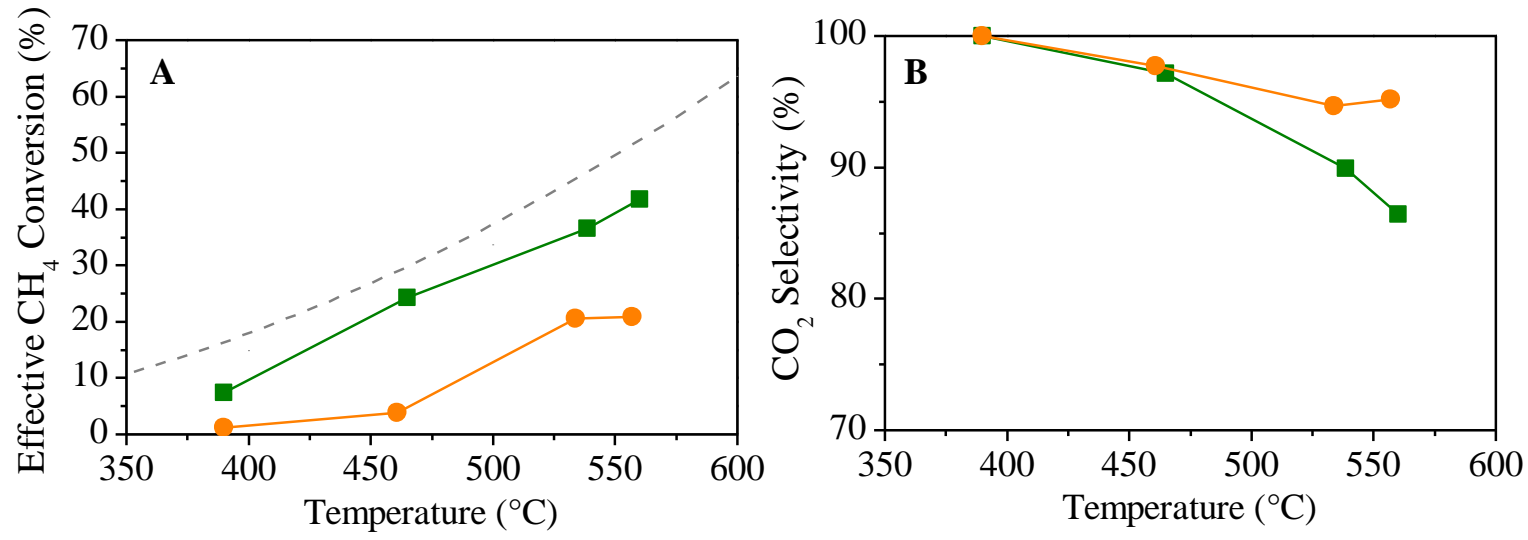

$\longrightarrow$ CHF $\longrightarrow$ CHFMR - Modified - - - Thermodynamic Equilibrium

Figure 6 - Temperature dependent effective methane conversion (A) and $\mathrm{CO}_{2}$ selectivity (B) of $\mathrm{CHF}$ and CHFMR modified to stopover $\mathrm{H}_{2}$ removal. 

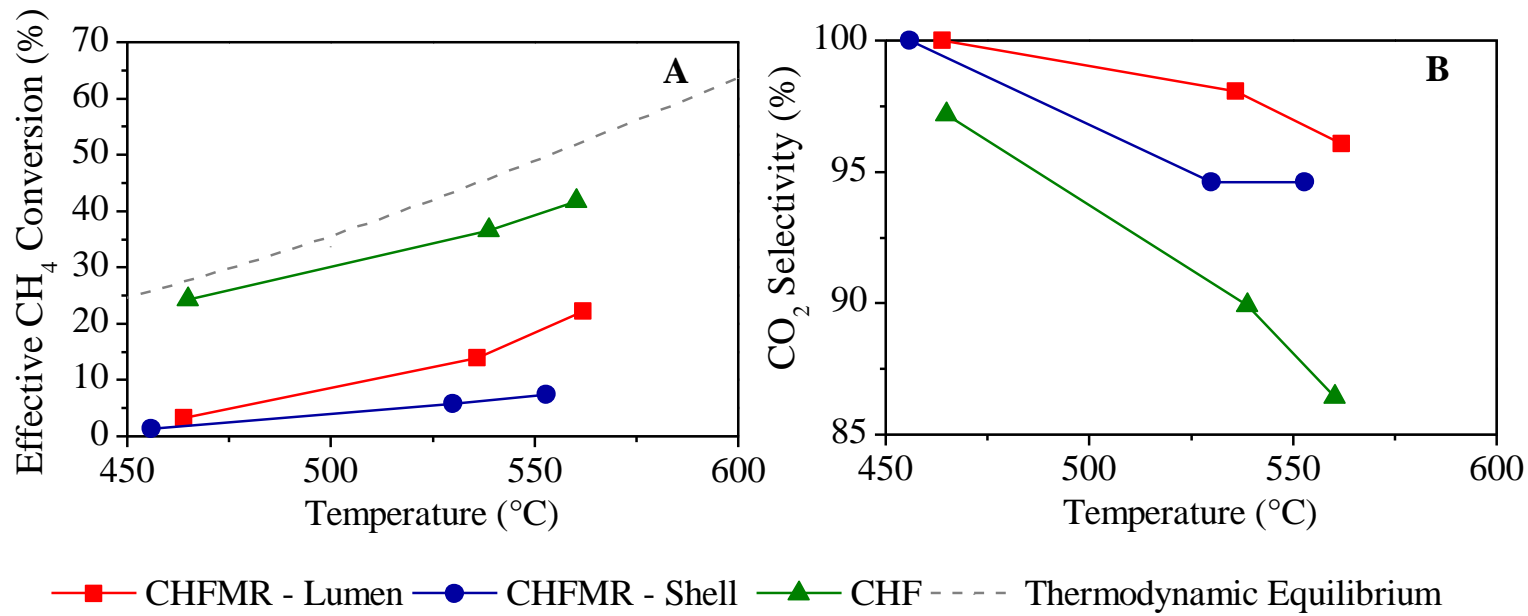

Figure 7 - Temperature dependent effective methane conversion (A) and $\mathrm{CO}_{2}$ selectivity (B) of CHF and CHFMR operated with addition $\mathrm{H}_{2}$ either in lumen or shell sides. 

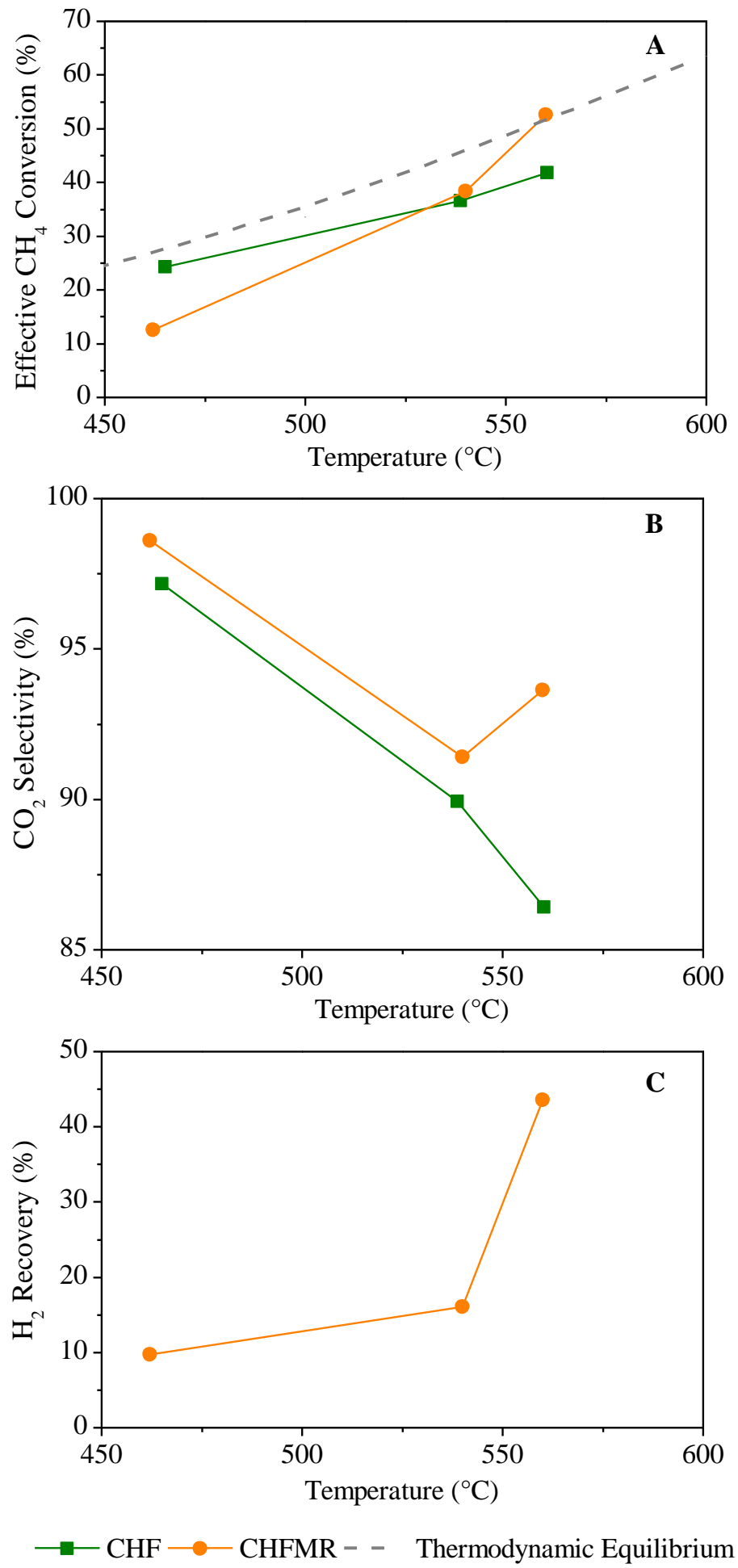

Figure 8 - Temperature dependent effective methane conversion (A) and $\mathrm{CO}_{2}$ selectivity (B) and $\mathrm{H}_{2}$ Recovery $(\mathrm{C})$ of CHF and CHFMR operated at single temperature. 